\title{
Comparison of antibacterial activity of Ciprofloxacin and Cephalexin against Some common bacterial Species isolates from donkey wounds around the vicinity of Tandojam Sindh Pakistan
}

Safia Arbab ${ }^{1 *}$, Rehana Shahnawaz Buriro ${ }^{1}$, Hanif Ullah $^{2}$, Shams Uddin Bhugio ${ }^{1}$, Atta Hussain $\mathrm{Shah}^{3}$, Dildar Hussain Kalhoro ${ }^{4}$, Muhammad Azhar Memon ${ }^{5}$, Sambreena Tunio ${ }^{3}$, Waseem Ali Vistro ${ }^{6}$, Ahmed Nawaz Khoso $^{7}$, Mehwish Rajput ${ }^{5}$ and Imtiaz Ali Ujjan ${ }^{8}$

1. Department of Veterinary Pharmacology, Sindh Agriculture University, Tandojam-Pakistan

2. Shanghai Veterinary Research Institute, Chinese Academy of Agriculture Sciences, Key Laboratory of Animal Parasitology, Shanghai 200241-China

3. Department of Animal Product Technology, Sindh Agriculture University, Tandojam-Pakistan

4. Department of Veterinary Microbiology, Sindh Agriculture University, Tandojam-Pakistan

5. Department of Veterinary Parasitology, Sindh Agriculture University, Tandojam-Pakistan

6. Department of Anatomy and Histology, Sindh Agriculture University, Tandojam-Pakistan

7. Department of Animal Breeding Genetics, Faculty of Veterinary and Animal Sciences, LUWMS, Uthal-Pakistan

8. Department of Veterinary Medicine, Sindh Agriculture University, Tandojam-Pakistan

*Corresponding author's email: safiakandhro@gmail.com

Citation

Safia Arbab, Rehana Shahnawaz Buriro, Hanif Ullah, Shams Uddin Bhugio, Atta Hussain Shah, Dildar Hussain Kalhoro, Muhammad Azhar Memon, Sambreena Tunio, Waseem Ali Vistro, Ahmed Nawaz Khoso, Mehwish Rajput and Imtiaz Ali Ujjan. Comparison of antibacterial activity of Ciprofloxacin and Cephalexin against Some common bacterial Species isolates from donkey wounds around the vicinity of Tandojam Sindh Pakistan. Pure and Applied Biology. Vol. 10, Issue 4, pp1095-1103. http://dx.doi.org/10.19045/bspab.2021.100114

\begin{tabular}{llll}
\hline \hline Received: 01/10/2020 & Revised: 28/12/2020 & Accepted: 11/01/2021 & Online First: 13/01/2021 \\
\hline \hline
\end{tabular}

\section{Abstract}

The results obtained in the current study have increased knowledge on bacterial infections of skin wounds in equines around the vicinity of Tandojam Sindh Pakistan and compare with two different antibiotics (Ciprofloxacin and Cephalexin) against some common pathogens. During this experiments, a total of 50 wound samples were collected from donkey wounds. Specimens were brought in a cold chain. All 50 samples were found contaminated with different bacterial organisms including Staphalococcus aureus (45\%), Escherichia coli (35\%), Shigella (33\%) and Salmonella spp (25\%). The isolated bacterial organisms were checked for their susceptibility against Cephalexin and Ciprofloxacin. S. aureus $(18 \mathrm{~mm})$, showed higher sensitivity against Cephalexin (18mm) and followed by Escherichia coli, $(15 \mathrm{~mm})$, Shigella $(13 \mathrm{~mm})$, and Salmonella spp. (13mm) respectively. Whereas Ciprofloxacin showed more significant activity against $S$. aureus $(24 \mathrm{~mm})$, E. coli $(20 \mathrm{~mm})$, Shigella $(15 \mathrm{~mm})$, and Salmonella spp. (18mm).The results of this 
study revealed that both antibiotics Ciprofloxacin and Cephalexin showed higher sensitivity against the isolated microorganisms. S.aureus showed greater susceptibility against Cephalexin, followed by Escherichia coli, Shigella, and Salmonella spp. In contrast, Ciprofloxacin showed higher activity against Staphylococcus aureus and E. coli, and minimum for Shigella and Salmonella spp.

Keywords: Antimicrobial effect; Antibiotics; Donkey wound; Gram negative; Gram positive bacteria

\section{Introduction}

The Donkey is a domesticated animal of the family Equidae. It has been used as a working animal from last 5000 years. There are more than 41.5 million donkeys in the world [1]. Several studies indicated that the antibiotic has a notable effect on donkey wound healing. Ciprofloxacin was introduced in 1980 and was first introduced in marketed in 1987 [2]. It is one of the most effective and safe medications on the list of global health organizations [3]. Ciprofloxacin is one of the best fluoroquinolones for wide clinical use and was previously known for its activity against a wide range of pathogens [4]. In previous studies, it was reported that fluoroquinolone was among the most commonly proposed class of antimicrobial drugs in communities and hospitals $[5,6]$. Cephalexin is effective against gram-positive and some gram-negative bacteria that disturb the growth of the cell wall of the bacteria. Cephalexin is the first generation cephalosporin, it is also known as betalactam antibiotic. Cephalexin has been used to treat some infectious diseases of the urinary tract, bones, joints, middle ear, and skin. It can also be used to prevent bacterial endocarditis, pneumonia and throat infection [7]. Other researchers have suggested that Salmonella was highly sensitive to ciprofloxacin and less sensitive cephalexin [7].

There are different kinds of open wounds; incised wound, laceration, abrasion, avulsion, puncture wound, penetration wound and gunshot wound [8]. Skin wound of a donkey can develop ideal condition where microorganisms can grow, especially in the wound cause by saddle (saddle sore), it may lead to secondary infection by providing suitable condition for the growth of microorganism. The typical signs of wound on equine skin include erythematic, pain, hotness and pyogenic discharge. Other symptoms in an advances stage include slow healing, friable granulation at the base of the lesion, odor, exudate and the pain increase when these wound disrupt due to reoccurrence of any injury $[9,10]$.

The open wound can be infected by contaminating wide range of microorganism such as bacteria, fungi and parasites [9]. The microorganisms, which are commonly involve in septic wound (infected wound), are gram positive such as hemolytic streptococcus $\beta$ : Streptococcus pyogenes and Staphylococcus aureus and gram-negative aerobic, such as Pseudomonas aeruginosa. In contrast, facultative anaerobes include, Escherichia coli, Klebsiella and Proteus, fungal organisms such as Candida species and molds (Aspergillus species) [8].

Several studies indicated that the antibiotic has a notable effect on wound healing. Therefore, very little work has been conducted on bacteria, which are isolated from donkey's wounds. Therefore, considering the importance of the donkey as a domesticated member of the horse family, Equidae, this study has been designed to isolate and identified the bacterial species from the wound and the antibacterial effect of Ciprofloxacin and Cephalexin against the bacterial isolates. 


\section{Materials and Methods \\ Study population and sampling}

In this study, a total of 50 different samples of saddle sore and other types of skin wounds from 50 donkeys were collected. Skin around the wound were disinfect by $70 \%$ alcohol to prevent from extraneous contamination. Sample were collected by using sterile swab and transported in a cold chain to the Department of Veterinary Pharmacology, SAU, Tandojam. Samples were cultured and processed for identification by using, morphological characteristics and biochemical properties. Followed by antisusceptibility test (AST) was determined by disc diffusion method described by Rind and Khan [11].

\section{Bacterial isolation and identification Primary culture}

Nutrient broth and Nutrient, MacConkey and Blood agar media were prepared and swab samples were cultured aerobically and anaerobically on these media and incubated at $37^{\circ} \mathrm{C}$ for $24 \mathrm{hrs}$. Colony characteristics were observed and smears were prepared, stained by Gram's staining and examined under the microscope for the identification of cell morphology.

\section{Sub-culture}

Further purification of cultures was prepared by sub culturing the well-separated colony on respective medium and repeated it severely. The purity of the samples were checked by examining stained smear. Followed by, the pure culture was grown onto agar slants and incubated at $37^{\circ} \mathrm{C}$ for $24 \mathrm{hrs}$. and stored at $4^{\circ} \mathrm{C}$. Further, the bacterial isolates were identified based on colony characteristic, microscopic morphology and biochemical properties such as catalase, oxidase, indole, coagulase, and triple sugar iron simmon citrate.

Staphalococcus aureus, Escherichia coli, Shigella and Salmonella spp were isolated from the donkey's wounds. Efficacy of selected anti-bacterial agents (Ciprofloxacin and Cephalexin) was determined against gram positive and gram-negative bacteria isolates.

\section{Detection of Staphylococcus aureus}

For the detection of Staphylococcus aureus, wound sample were sub cultured on the nutrient agar. Growth plates were observed for such as yellow golden colonies; further confirmation was done by Gram's staining and biochemical reactions of the isolates.

Detection of $E$. coli

For the detection of $E$. coli, wound samples were subcultured on the MacConkey's agar which is typical for E.coli growth. Growth plates were observed for bacterial growth, which included pink colonies on MacConkey's agar, and further confirmation was done by Gram's staining and biochemical test of the isolates.

\section{Detection of Salmonella and Shigella Spp}

For the detection of Salmonellal Shigella spp., wound samples were subcultured on the Salmonella /Shigella agar (SS Agar), which is specific for Salmonella and Shigella spp. Growth plates were observed for typical colonies such as for Shigella, as transparent or translucent colorless colonies. Colony characteristic may appear with or without black centers, and further confirmation was done by Gram's staining and biochemical test of the isolates.

Determination resistance profile of antibiotic Susceptibility Testing (AST) and Multiple antibiotic resistance (MAR) Index

Disk diffusion method was used to determine the AST test against some selected antibiotics of isolated bacteria [11]. The isolated bacteria were cultured by swabbing on the nutrient agar overnight and commercial antibiotic disk (HiMedia Laboratories, India) were placed on the swabbed plate aseptically and incubated at $37^{\circ} \mathrm{C}$ for $24 \mathrm{hrs}$. The clear zones were formed around the disc which were recorded in $\mathrm{mm}$ (millimeter) by using $\mathrm{Hi}$ Antibiotic Zone Scale (HiMedia). The MAR 
index were determined for each bacterial species;

MAR Index $=\underline{\text { No. } \text { of antibiotic to which isolates are resistant }}$ No. of antibiotic test

\section{Results}

In the current study, we compare the antibacterial activity of two standard antibiotics against some common pathogenic bacterial isolates from donkey wound.

The percentage prevalence of bacterial organisms isolated from donkey wound

A total of 50 wound samples were examined and all were recorded positive for different organisms. Out of 50 samples, 45, 35, 33, and 25 number were found positive for Staphylococcus aureus, Escherichia coli, Shigella and Salmonella spp. respectively (Table 1). All organisms were identified on their morphological, cultural characteristics and staining reactions. Organisms were further confirmed by their biochemical reactions.
Susceptibility of isolated organisms against different antibiotics

It provides the basis to test the sensitivity, and the zone of inhibition around disk determined resistances according to reference standards. The following antibiotic discs were used: Ciprofloxacin and Cephalexin, as shown in (Table 2).

Antibiotics i-e Cephalexin and Ciprofloxacin were used during this study; both are broadspectrum antibiotics as this work against gram-negative as well as gram-positive bacteria. For Cephalexin, S. aureus showed greater susceptibility $(18 \mathrm{~mm})$, followed by E.coli (15 mm), Shigella and Salmonella (13 $\mathrm{mm})$ respectively, whereas Ciprofloxacin produced maximum sensitivity for S.aureus and E.coli (20 to $24 \mathrm{~mm}$ ) minimum for Shigella and Salmonella spp (15 to $18 \mathrm{~mm}$ ). With respect to individual pathogens, antibiotics showed sensitivity against grampositive as well as gram-negative isolate (Table 3).

Table 1. The number and percentage prevalence of bacterial organisms isolated from donkey wounds

\begin{tabular}{|c|c|c|c|c|c|}
\hline Bacterial species & $\begin{array}{c}\text { Total No. of } \\
\text { wound } \\
\text { sample }\end{array}$ & $\begin{array}{c}\text { No. of positive } \\
\text { wound sample }\end{array}$ & $\begin{array}{c}\text { Percentage } \\
(\%)\end{array}$ & $\begin{array}{c}\text { No. of negative } \\
\text { Wound sample }\end{array}$ & $\begin{array}{c}\text { Percent } \\
\text { age (\%) }\end{array}$ \\
\hline $\begin{array}{c}\text { Staphylococcus } \\
\text { aureus }\end{array}$ & 50 & 45 & $90 \%$ & 5 & $10 \%$ \\
\hline Escherichia coli & 50 & 35 & $70 \%$ & 15 & $30 \%$ \\
\hline Shigellaspp & 50 & 33 & $66 \%$ & 17 & $35 \%$ \\
\hline Salmonella spp & 50 & 25 & $50 \%$ & 25 & $50 \%$ \\
\hline
\end{tabular}

Table 2. The zones of inhibition were observed and recorded with the following annotations

\begin{tabular}{|c|c|c|}
\hline Description & Significance & Sensitivity level \\
\hline Absence of clear zone & No sensitivity & + \\
\hline Clear zone with $1-2 \mathrm{~mm}$ & Weakly sensitivity & ++ \\
\hline Clear zone with $3-7 \mathrm{~mm}$ & Moderately sensitivity & +++ \\
\hline Clear zone with $7-11 \mathrm{~mm}$ & Quite sensitivity & ++++ \\
\hline Clear zone with $12-15 \mathrm{~mm}$ or above & Highly sensitivity & + \\
\hline
\end{tabular}


Table 3. Zones of inhibition produced by different antibiotics against bacterial isolates

\begin{tabular}{|c|c|c|c|c|}
\hline \multicolumn{5}{|c|}{ Zones of inhibition (In mm) against Antibiotics } \\
\hline Bacterial species & Ciprofloxacin & $\begin{array}{c}\text { Sensitivity } \\
\text { Cephalexin }\end{array}$ & Sensitivity \\
\hline Staphylococcus aureus & $24 \mathrm{~mm}$ & $\begin{array}{c}\text { Highly sensitive } \\
(+++)\end{array}$ & $18 \mathrm{~mm}$ & $\begin{array}{c}\text { Highly sensitive } \\
(++++)\end{array}$ \\
\hline Escherichia coli & $20 \mathrm{~mm}$ & $\begin{array}{c}\text { Highly sensitive } \\
(++++)\end{array}$ & $15 \mathrm{~mm}$ & $\begin{array}{c}\text { Highly sensitive } \\
(++++)\end{array}$ \\
\hline Shigellaspp & $18 \mathrm{~mm}$ & $\begin{array}{c}\text { Highly sensitive } \\
(++++)\end{array}$ & $13 \mathrm{~mm}$ & $\begin{array}{c}\text { Highly sensitive } \\
(++++)\end{array}$ \\
\hline Salmonellaspp & $15 \mathrm{~mm}$ & $\begin{array}{c}\text { Highly sensitive } \\
(++++)\end{array}$ & $13 \mathrm{~mm}$ & $\begin{array}{c}\text { Highly sensitive } \\
(++++)\end{array}$ \\
\hline
\end{tabular}

\section{Discussion}

The study was conducted to investigate and isolate the bacteria which are associate with equine wounds around the vicinity of Tandojam Sindh Pakistan. The results of this study shows that, 4 different species of aerobic and anaerobic bacteria namely: $S$. aureus, E. coli, Shigella and Salmonella spp were isolated from the different wound of donkeys. These findings of this studies were agreement to the previous study by [11] who isolated different species of aerobic and anaerobic bacteria from the non-surgical (injured) and surgical wounds located on body surface of animals.

Similar findings were also reported by [12] they reported most prevalent bacterial species was Staphylococcus spp from equine wounds . Four bacterial species were recognized from wound samples of donkey's wounds. Staphylococcus aureus, Escherichia coli Salmonella and Shigella spp and their incidence percentages recorded were $90 \%$, $70 \%, 66 \%$ and $50 \%$ respectively (Table 2 ). This finding could be related to bacterial organisms from wound samples of animals by various workers throughout the world. However, the comparison of the present figures (Fig. $1 \& 2$ ) can be compared with the results of [11]. They isolated and characterized bacterial species from nonsurgical and surgical wounds located on skins and hides of domestic animals. Their results showed Staphylococcus aureus as most common organisms, followed by Escherichia coli and Bacillus spp. from buffaloes, cattle, sheep and goat wounds, another study showed that Staphylococcus, isolates are the common pathogens from injuries of dogs [12]. The finding of our results may be associate with the pathology of Staphylococcus spp, which are capable of producing various toxin and enzyme, which may facilitate the colonization and invasion of infection better than other bacteria.

The results of this study shows that, the prevalence of salmonella spp was $50.0 \%$. Similar bacterial isolates were also investigated by [13] with $95 \%$ and CI range from 3.93 to 26.07 with reasonable explanation. This may be because Salmonella spp and Streptococcus spp are less virulent and cause less severe and non-invasive infection but variable numbers of organism may be found on the skin lesion. However, the least prevalent bacteria on the skin wound are Pseudomonas spp, E. coli, Clostridium spp, Shigella spp and Klebsiella spp. Similar results were also reported on the wounds of equines by $[10,13,14]$.It is reported that, the growth of these bacteria are inhibited either due immunity of an animal against these bacteria, or micro-environment of the wound and competitive inhibition by other virulent microbes (Staphlococcus spp) [15].

In this study, the contaminated skin wound were most commonly found at the back area and both sides of abdomen. The findings are agreement to previous study by [16] which may be due to, the back and both sides of 
abdomen are constantly covered with saddles and harness for a longer period of time in a day. The profuse sweating resulting from strenuous work during the warm hours of the day and continuous abrasive movement of poor saddle and hareness macerates the skin over these areas and this may lead to abrasion and result in damaging the skin barrier.

In addition, the longtime covering of saddle and harness increases the warmth of these regions of the body which may lead to deprivation of air at these region and this may create suitable microenvironment that would be favorable for the growth of microorganism. The donkeys are highly susceptible to the similar infections as compare to horse this may be due to different managemental practices and variation in number of tested sample in the two investigated area. The results of our finding are in contrast of the findings reported by [16]. It was reported that, not all the bacteria, which were isolated from a wound, are susceptible to the single antibiotic. The antibiotic sensitivity pattern of the bacteria, which were isolate, showed resistant against one or multiple antibiotic drugs [15] Similar results were also reported in the present study with the most resistant and susceptible bacteria was Shigella and $S$. aureus respectively. Moreover, it is also reported in this study that, ciprofloxacin was highly effective antibiotic against all the bacterial isolates and less effective against cephalexin whereas it is reported by [15] that, the highly sensitive antibiotics which are effective against the bacterial isolates from the wound were gentamicin, chloramphenicol, amikacin, gatiflaxacin and sparflaxacin. The appropriate choice of antibiotic for wound infection is extend spectrum ciprofloxacin (Fluoroquinolone). Moreover, The highest prevalent bacteria which was isolated from the wound was S.aureus $(30.7 \%)$ and the pattern of sensitivity of Ciproflaxcin was $78.9 \%$ against the $S$. aureus which was being considered as active antibiotic against the bacterial speies [17]. It was also reported in this study that, the zone of inhibition was larger against S.aureus (20-25mm). The results of present study was agreement to previous study by [10]. He reported that, the larger zones of growth inhibition was produced by Tetracycline, ampicillin and ciprofloxacin against the $S$ aureus and S.pyogenes. Similar research was carried out, and it was found that most effective antibiotic for gram positive as well as gram negative is Meropenem followed by Cefoperazone with $100 \%$ efficacy. It is reported that, all the isolates which were resistant to Doxycycline and the rate of susceptibility against erythromycin and ciprofloxacin was $54.55 \%$ [18]. The current study also showed agreement with previous studies [19, 20]. 

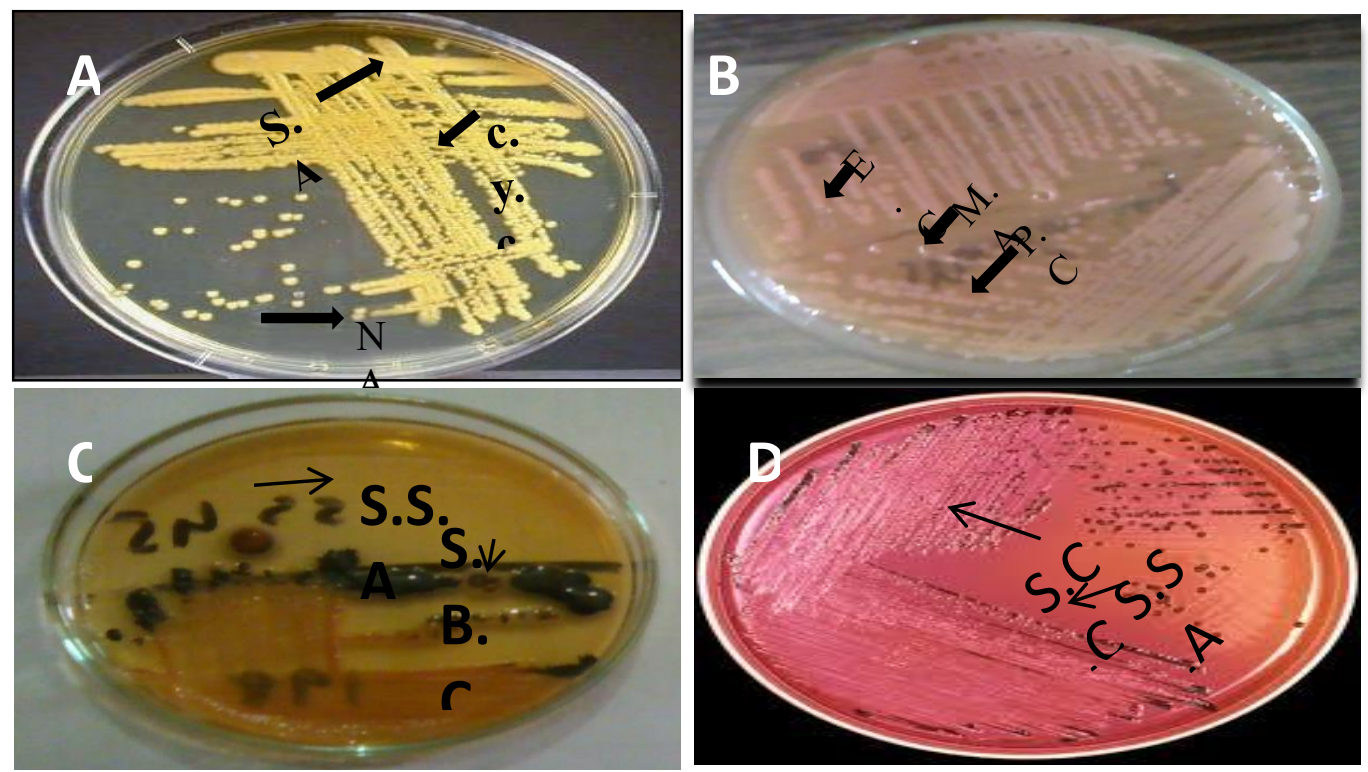

Figure 1. Plate-(a) showing the culture characteristics Staphylococcus aurous $(\mathrm{S} . \mathrm{A})$ golden yellow colonies (CYC) on nutrient agar (NA) plate- (b) showing the culture characteristics Escherichia coli (EC) pink colonies (PC) on MacConkey's agar (MA). Plate- (c) showing the culture characteristics Salmonella black center (SBC) black colonies (BC) on S.S agar. Plate(d)is showing the culture characteristics of Shigella colorless colonies (SCC) on S.S agar.
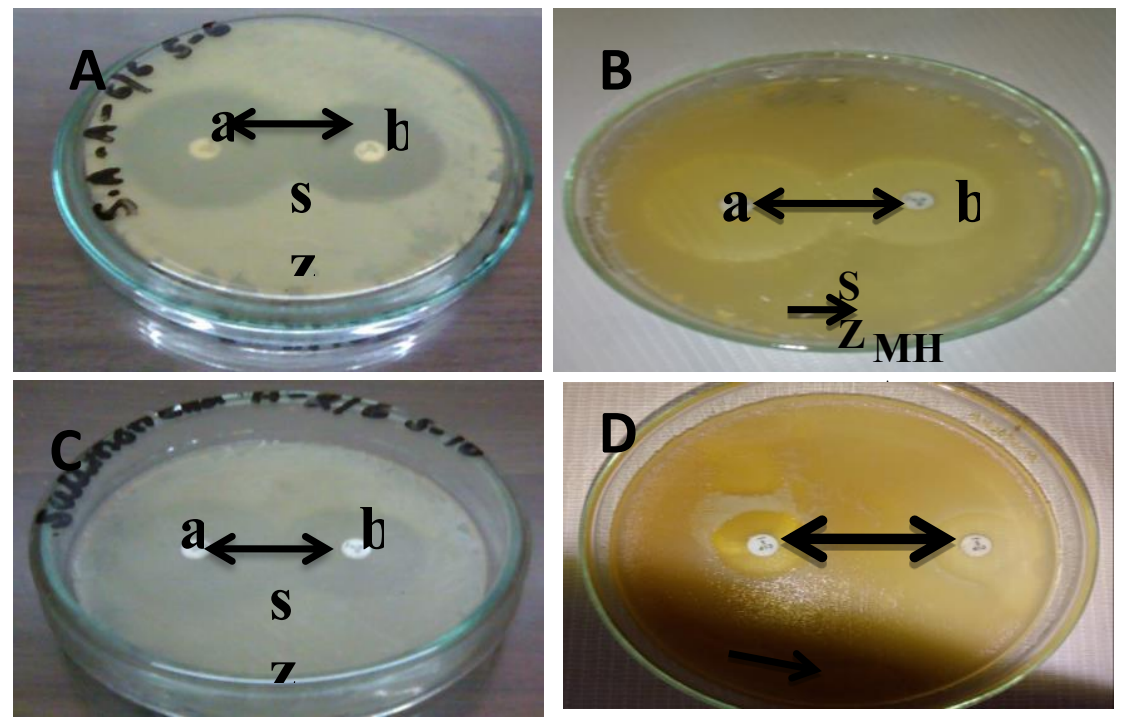

Figure 1. Plate (a) - showing sensitivity zones (SZ) produced by two different antibiotics against Staphylococcus aureus on Muller- Hinton agar plate (MHA) (a) Ciprofloxacin and (b) Cephalexin Plate - (b) showing sensitivity zones (SZ) produced by two different antibiotics against Escherichia coli on Muller- Hinton agar plate (MHA) (a) Ciprofloxacin and (b) Cephalexin Plate- (c) showing sensitivity zones (SZ) produced by two different antibiotics against Salmonella on Muller- Hinton agar plate (MHA) (a) Ciprofloxacin and (b)Cephalexin Plate- (d) showing sensitivity zones (SZ) of inhibition produced by two different antibiotics against Shigella on Muller- Hinton agar plate (MHA) (a) Cephalexin and (b) Ciprofloxacin 


\section{Conclusion}

It is conclude that, Staphylococcus aureus were the most prevalent bacteria in equine wound followed by Escherichia coli, Shigella, and Salmonella spp. It is also concluded that the bacterial species, which were isolated, are either resistant to single of multiple antimicrobial drug resistance. Ciprofloxacin showed higher sensitivity against the $\mathrm{S}$ aureus as compare to cephalexin. The variety of organisms were observed in this study support the need to obtain culture specimens from infected wounds for microbiological evaluation and antibiotic susceptibility determination so that adapted chemotherapy can be prescribed. We also suggest that we should educate the owner on the public health and improve their managemental practices, which will help enhance wound healing.

\section{Authors' contributions}

Conceived and designed the experiments: $\mathrm{S}$ Arbab \& R Buriro, Performed the experiments: $\mathrm{S}$ Bhugio, AH Shah \& Hanifullah, Analyzed the data: S Bhugio, AH Shah \& D Kalhoro, Contributed reagents/ materials/ analysis tools: IA Ujjan, S Tunio, WA Vistro \& AN Khoso, Wrote the paper: S Arbab, MA Memon \& M Rajput.

\section{Acknowledgments}

The authors thankful to the Department of Veterinary Pharmacology, Animal production technology Laboratory, Faculty of Animal Husbandry and Veterinary Sciences, Sindh Agriculture University Tandojam for providing facilities to finish this research work.

\section{References}

1. Abebew D, Endebu B \& Gizachew A (2011). Status of parasitism in donkeys of project and control areas in central region of Ethiopia: a comparative study. Ethiop Vet J 15.

2. Su HC, Ramkissoon K, Doolittle J, Clark M, Khatun J, Secrest A, Wolfgang MC, \& Giddings MC (210) The development of ciprofloxacin resistance in Pseudomonas aeruginosa involves multiple response stages and multiple proteins. Antimicrob Agents Chemother 54: 4626-4635.

3. WHO Model List of Essential Medicines-19th List. April 2015Amended November 2015. Available at: WHO.

Int/medicines/publications/essentialmed icines/en/.

4. Sharma D, Patel RP, Zaidi STR, Sarker M, Rahman M, Lean QY \& Ming LC (2017). Interplay of the quality of ciprofloxacin and antibiotic resistance in developing countries. Frontiers in Pharmacol 8: 546.

5. Harnett N, Brown $\mathrm{S}$ \& Krishnan $\mathrm{C}$ (1991). Emergence of quinolone resistance among clinical isolates of methicillin-resistant Staphylococcus aureus in Ontario, Canada. Antimicrob. Agents Chemother 35: 1911-1913.

6. Mendes-Bastos P, Carvalho R, Cunha D \& Cardoso J (2014) Ciprofloxacin: an uncommon drug reaction to a commonly used drug. Korean J Intern Med 29: 263.

7. Zhang XF, Wang HM, Song Y, Nie LH, Wang, LF, Liu B, Shen PP \& Liu Y (2006). Isolation, structure elucidation, antioxidative and immunomodulatory properties of two novel dihydrocoumarins from Aloe vera. Bioorg Med Chem Lett 16: 949-953.

8. Wells D, Krecek R, Wells M, Guthrie A \& Lourens J (1998). Helminth levels of working donkeys kept under different management systems in the Moretele 1 district of the North-West Province, South Africa. Vet Parasitol 77: 163-177.

9. Bowler P, Duerden B \& Armstrong DG (2001). Wound microbiology and associated approaches to wound management. Clin Microbiol Rev 14: 244-269. 
10. Devrajani K, Abubakar M, Fazlani A, Shahid F, Ourban A \& Imran R (2010). Occurrence and prevalence of bacterial species as identified from camel wound. Inter J Agro Vet Med Sci 4: 96-104.

11. Rind R \& Khan $\mathrm{T}$ (2000). Bacteriological studies on surgical and non-surgical wounds located on body surface of animals. Pak J Biol Sci.

12. Kelly P, Mason P, Els J \& Matthewman L (1992). Pathogens in dog bite wounds in dogs in Harare, Zimbabwe. Vet Rec 131: 464-466.

13. Mamman PH, Mshelia WP \& IE F (2011). Antimicrobial Susceptibility of Aerobic Bacteriaand Fungi Isolated from Cases of Equine Ulcerative Lymphangitis in Kano Metropolis, Nigeria. Asian J Anim Sci 5: 175-182.

14. Abrahamian FM \& Goldstein EJC (2011). Microbiology of animal bite wound infections. Clin Microbiol Rev 24: 231-246.

15. Tiwari R, Yadav SK \& Singh S (2015) Bacterial etiology of skin and wound infections along with antibiogram profiling in reference to emerging antibiotic resistance in animals. $A d v$ Anim Vet Sci 3: 259-268.
16. Mohammad IA (2002) Bacteria of Infected Wounds in Equines in Khartoum State. MSc Thesis. University of Khartoum, Khartoum, the Sudan.

17. Onwubiko NE \& Sadiq NM (2011). Antibiotic sensitivity pattern of Staphylococcus aureus from clinical isolates in a tertiary health institution in Kano, Northwestern Nigeria. Pan African Medical Journal, 8.

18. Olaleye M \& Bello-Michael C (2005). Comparative antimicrobial activities of Aloe vera gel and leaf. Afr J Biotechnol (12) 4 .

19. Jothi KR, Vijayalakshmi K, Tamilarasi L \& Balasubramanian E (2014). Antibacterial activity of leaf extracts of Aloe Vera, Ocimum Sanctum and Sesbania Grandiflora against the Gram positive bacteria. Asian $J$ Biomed Pharma Sci 4: 60-63.

20. Sebiomo A, Awofodu A, Awosanya A, Awotona F \& Ajayi A (2011). Comparative studies of antibacterial effect of some antibiotics and ginger (Zingiber officinale) on two pathogenic bacteria. J Microbiol Antimicrob 3: 1822. 